\title{
Ezrin Distribution Is Abnormal in Principal Cells from a Murine Model of Autosomal Recessive Polycystic Kidney Disease
}

\author{
STEPHANIE A. ORELLANA, ANDREA M. QUIÑONES, AND MARYLOU L. MANDAPAT
}

Departments of Pediatrics [S.A.O., A.M.Q., M.L.M.] and Physiology and Biophysics [S.A.O.], Case Western Reserve University School of Medicine and The Rainbow Center for Childhood PKD, Rainbow Babies and Children's Hospital, University Hospitals of Cleveland, Research Institute, Cleveland, Ohio 44106-6003, U.S.A.

\begin{abstract}
Abnormalities in cell proliferation and intracellular signaling are features of inherited human and murine polycystic kidney diseases (PKD), regardless of the primary genetic defects. Loss of protein kinase A regulation of cell proliferation has been reported in the murine $\mathrm{C} 57 \mathrm{BL} / 6 \mathrm{JCys} 1^{c p k-/-}(c p k)$ model of autosomal recessive PKD. Qualitative differences in protein kinase A subunit distribution were observed between filter-grown cultures of noncystic- (C57BL/6J mice) and cystic $c p k$-derived principal cells. It was hypothesized that protein kinase A subunit distribution differences were mediated by differences in A-kinase anchoring protein (AKAP) expression, so expression of four AKAPs was examined in filter-grown cultures of primary murine cystic- and noncystic-derived principal cells. AKAP-KL expression was ambiguous, but mAKAP, AKAP95, and ezrin were expressed at expected molecular sizes and cellular locations in noncystic-derived cells. Perinuclear mAKAP and nuclear AKAP95 were distributed normally in $c p k$-derived cells. Expression of AKAP95 in cystic epithelium was diminished relative to controls, and ezrin expression was modestly decreased and abnormally distributed within a region near the apical surface. Qualitative differences were observed in ezrin location in response to medium change or stimulation with epidermal growth
\end{abstract}

\section{ABSTRACT}

factor which suggested cell-specific differences may result from the $c p k$ mutation or the abnormal epidermal growth factor receptor phenotype that characterizes PKD. Ezrin has been implicated in tubulogenesis, so altered ezrin expression or function could be disruptive. If PKD mutations that contribute to PKD pathogenesis are postulated to disrupt normal tubular development, perhaps the mechanism includes altered ezrin function and abnormal protein kinase A targeting. (Pediatr Res 54: 406-412, 2003)

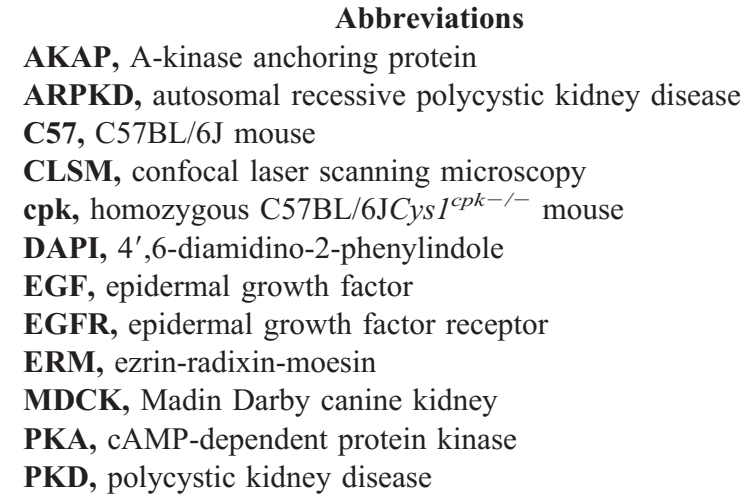

Human PKDs, autosomal dominant PKD and ARPKD, is distinguished by epithelial proliferation and progressive fluid accumulation in renal tubules to form cysts, which can lead to renal failure [for review see Davis et al. (1)]. Six genes responsible for human, murine, and rat PKD family members have been identified (2-7), but whereas the known gene products (polycystin-1, polycystin-2, fibrocystin, cystin, and po-

Received July 13, 2002; accepted March 11, 2003.

Correspondence: Stephanie A. Orellana, Ph.D., Department of Pediatrics, 11100 Euclid Avenue, Mail Stop 6003, Cleveland, OH 44106-6003, U.S.A.; e-mail: sao3@po.cwru.edu Supported by National Institutes of Health grants DK50707; by the PKD Foundation; and by the Department of Pediatrics of Rainbow Babies and Children's Hospital of the University Hospitals of Cleveland.

DOI: 10.1203/01.PDR.0000077480.82519.E1 laris) have been postulated to form membrane-associated signaling complexes involved in normal nephrogenesis, and polycystin-1 specifically mediates tubulogenesis in two renal cell lines $(8,9)$, a specific mechanistic pathway leading directly from abnormal gene expression to renal cyst formation has yet to be described.

Compartmentalization of cAMP action can occur via the association of individual AKAPs with specific PKA subtype activities. Inasmuch as AKAPs may permit assembly of signaling complexes $(10-12)$, the association of individual AKAPs with specific PKA substrates could provide a mechanism for linking and targeting PKA subtype regulation [for review, see Steinberg and Brunton (13)] to control of polarized epithelial cell functions. Our previous reports demonstrated 
differences in PKA subunit distribution that predicted differences in PKA subtype distribution and function in collecting tubular epithelial cell cultures (14-17). Roles for cAMP in the family of inherited human and murine PKDs have been postulated by us and others [for reviews, see Marfella-Scivittaro et al. (15) and Calvet and Grantham (18)]; thus, the present study was undertaken to evaluate potential mechanisms for subcellular PKA distribution and differences in proliferation previously observed between noncystic and cystic renal epithelial cell models. Because AKAPs can mediate PKA subunit distribution and act as a foundation for signaling complexes, expression of AKAPs known to be associated with cytoskeletal and nuclear structures was examined in normal and cysticderived murine principal cell cultures.

\section{METHODS}

Cell isolation and culture. An animal model of ARPKD, the cpk mouse (19), arose from spontaneous mutation in the C57 strain. The murine disease phenotype and its progression mimic the human disease ARPKD [for reviews, see Avner (20) and Sweeney and Avner (21)]. Enriched populations of untransformed principal cells from both $\mathrm{C} 57$ and $c p k$ animals were isolated and cultured on Transwell-Clear filter inserts (Corning Costar Corp., Lake Placid, NY, U.S.A.) as described (15). All cultures were confluent when assayed. Use of animals for this study was approved by the Case Western Reserve University Institutional Animal Care and Use Committee.

Immunologic reagents. Primary antibodies used were antiezrin (E8897, Sigma Chemical Co., St. Louis, MO, U.S.A.); anti-AKAP-KL (A81420, BD Transduction Laboratories, Lexington, KY, U.S.A.); anti-mAKAP (07-087, Upstate Biotechnology Inc., Lake Placid, NY, U.S.A.); and anti-AKAP95 (sc-6447, Santa Cruz Biotechnology, Inc., Santa Cruz, CA, U.S.A.). The fluorescent-tagged secondary antibodies used were Alexa-Fluor 488 donkey anti-goat conjugate (A-11055); Alexa-Fluor 594 donkey anti-goat conjugate (A-11058); Oregon Green 488 goat anti-mouse conjugate (O-6380); Oregon Green 488 goat anti-rabbit conjugate (O-6381); Texas Red-X goat anti-mouse conjugate (T-6390); and Texas Red-X goat anti-rabbit conjugate (T-6391; all from Molecular Probes, Eugene, OR, U.S.A.). Peroxidase-linked secondary antibodies used were goat anti-rabbit (sc-2004); goat anti-mouse (sc2005); and donkey anti-goat (sc-2020; all from Santa Cruz Biotechnology, Inc.).

Western analysis of protein expression. Protein samples (15 $\mu \mathrm{g}$ each) were subjected to Western analysis as previously described (15). Equal sample loading was required because comparative expression of a protein like actin, constitutively expressed in many normal tissues, was unsuitable for cystic tissues in which actin expression was abnormal (15), and in which actin isoforms may be down-regulated (22). Specific primary and secondary antibody combinations are indicated in the legend (Fig. 1), and densitometric quantitation of immunoreactive bands was performed using Scion Image v.4.0.2 software (Scion Corp., Frederick, MD, U.S.A.) and a flatbed scanner as described (23). For additional analyses, blots were stripped with the Re-Blot Plus Strong antibody stripping solu-

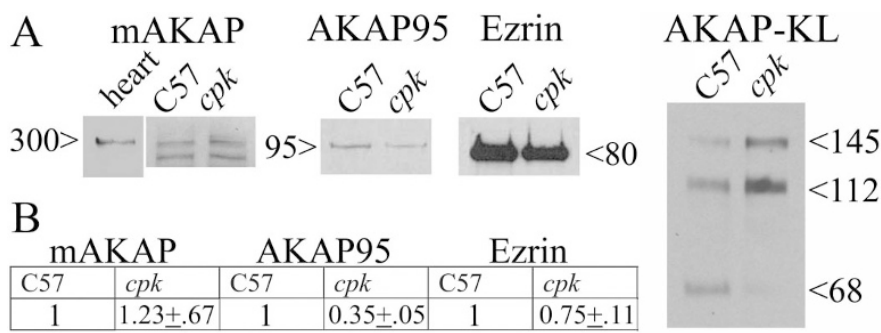

Figure 1. Murine principal cell cultures expressed AKAPs.Confluent filtergrown cultures of cystic $c p k$ and noncystic C57 - derived principal cells were subjected to Western analysis as described in Methods. A, Western analysis: primary antibodies described in "Methods" were used at the following dilutions: anti-mAKAP (07-087), 1:750; anti-AKAP95 (sc-6447), 1:750; antiezrin (E8897), 1:750; and anti-AKAP-KL (A81420), 1:750. Appropriate secondary antibodies described in "Methods" were used at the following dilutions: sc-2004, 1:3000; sc-2020, 1:1500; and sc-2005, 1:1500. Apparent molecular weights are indicated as kilodaltons. Control analyses performed in the absence of primary antibodies resulted in no signal (data not shown). Protein loaded was $15 \mu \mathrm{g} /$ lane. Results are representative of three experiments. $B$, relative expression: specific immunoreactive bands shown in $A$ were subjected to densitometric scanning and quantitation as described in "Methods." Expression is shown in arbitrary units. For each separate experimental pair (C57 and $c p k$ ), the C57 value was set at 1, and the corresponding cpk value was expressed relative to the $\mathrm{C} 57$ value. Values shown are mean $\pm \mathrm{SEM}, n=3$ experiments.

tion (2504, Chemicon International, Temecula, CA, U.S.A.) according to the manufacturer's instructions, and stripping time was increased by $5 \mathrm{~min}$ for each subsequent incubation.

Localization studies. For cultures treated before fixation, growth medium was removed and cultures were incubated at $37^{\circ} \mathrm{C}$, in fresh defined medium (21) lacking serum and containing additions indicated in figure legends. Paraformaldehyde fixation, immunostaining, and sample mounting were performed as described (15), using antibody combinations listed in figure legends (Figs. 2-4). Specificity was demonstrated using controls lacking primary antibodies, which in all cases resulted in no detectable fluorescent signal (data not shown). Actin labeling was performed using Oregon Green 514phalloidin conjugate (O-7465, Molecular Probes), which labels F-actin (15). Nuclear staining was performed after immunofluorescent labeling was completed, using propidium iodide (Molecular Probes) (15) or VectaShield with DAPI (H-1200, Vector Laboratories, Inc.).

Two methods were used to localize specific proteins identified by immunofluorescence $(14,15)$. Immunoreactive signals for all AKAPs examined were detected by standard fluorescence microscopy, using an Optiphot-2 fluorescence microscope with fluorescein isothiocyanate, Texas Red, and DAPI filter sets (Nikon Corp., Tokyo, Japan). Samples were photographed with a SPOT digital color camera (Diagnostic Instruments, Sterling Heights, MI, U.S.A.). Semitransparent layered images were constructed with Adobe PhotoShop 5.5 software [Adobe Systems Incorporated, San Jose, CA, U.S.A.; Figs. 2 and $4(15)]$.

CLSM was used to localize immunoreactive proteins as described $(14,15)$. A full $z$-series of $x-y$ scans was performed from above the epithelial layer and into the filter support, a depth typically ranging from approximately 6 to $11 \mu \mathrm{m}$. The full $z$-series was used to reconstruct the $x-z$ cross-sections 

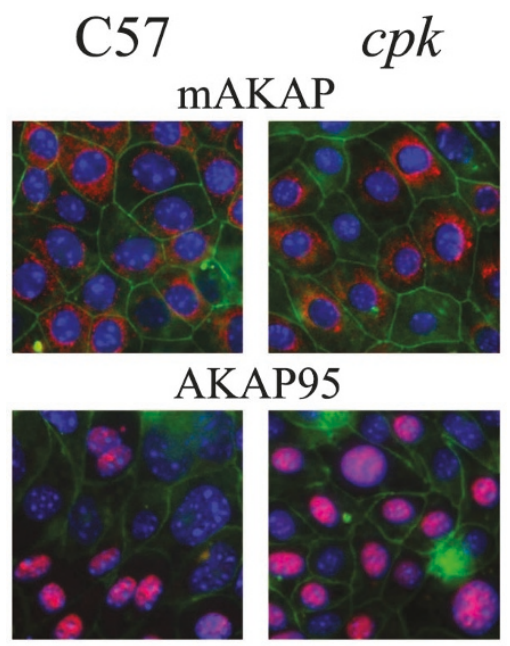

Ezrin

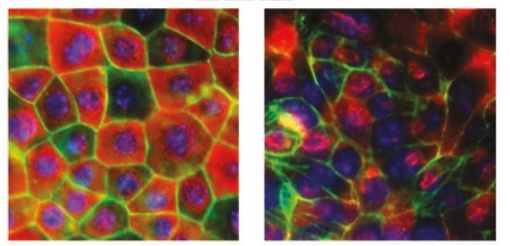

AKAP-KL

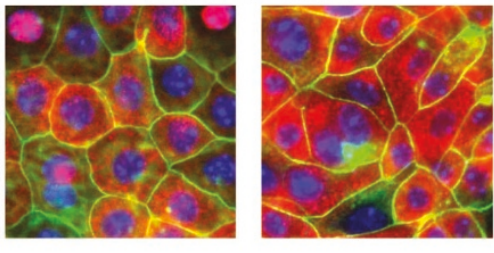

$\overline{25 \mu \mathrm{m}}$

Figure 2. Only $c p k$ ezrin expression was clearly abnormal compared with C57 when the cellular distribution of each AKAP was examined in principal cell cultures that formed confluent epithelial layers. Confluent filter-grown cultures of cystic $c p k$ - and noncystic C57-derived principal cells were subjected to fixation and immunostaining as described in "Methods." Primary antibodies described in "Methods" (anti-mAKAP, 07-087; anti-AKAP95, sc-6447; anti-ezrin, E8897; and anti-AKAP-KL, A81420) were used at 1:100 dilutions. Appropriate (red or green) fluorescent-conjugated secondary antibodies described in "Methods" (T-6391 or O-6381; A-11058 or A-11055; and T-6390 or O-6380; respectively) were used at 1:250 dilutions. Controls performed in the absence of primary antibodies resulted in no detectable fluorescent signals (data not shown). After immunostaining by fluorescent red-conjugated antibodies, samples were stained with a fluorescent greenconjugated phalloidin (to detect F-actin and approximate the location of cell boundaries) and DAPI (to detect nuclei, blue), as described in "Methods." Images shown are representative of three fields per sample, of one to two samples per experiment, of two to three experiments. Samples were viewed by conventional fluorescence microscopy, and images were captured, as described in "Methods." Individual red, green, and blue images were layered using Adobe PhotoShop 5.5 software. Magenta corresponds to regions of overlap between red and blue images. Bar represents $25 \mu \mathrm{m}$.

shown (Fig. 3). Enlargements shown were made using Adobe PhotoShop 5.5 software to select and increase the size of the regions between the white lines.

Tests of ezrin redistribution were performed by treatment of live cell cultures, fixation, and staining, as indicated above and in the legend to Figure 4. For each sample, 10 separate regions were viewed by conventional fluorescence microscopy as de-
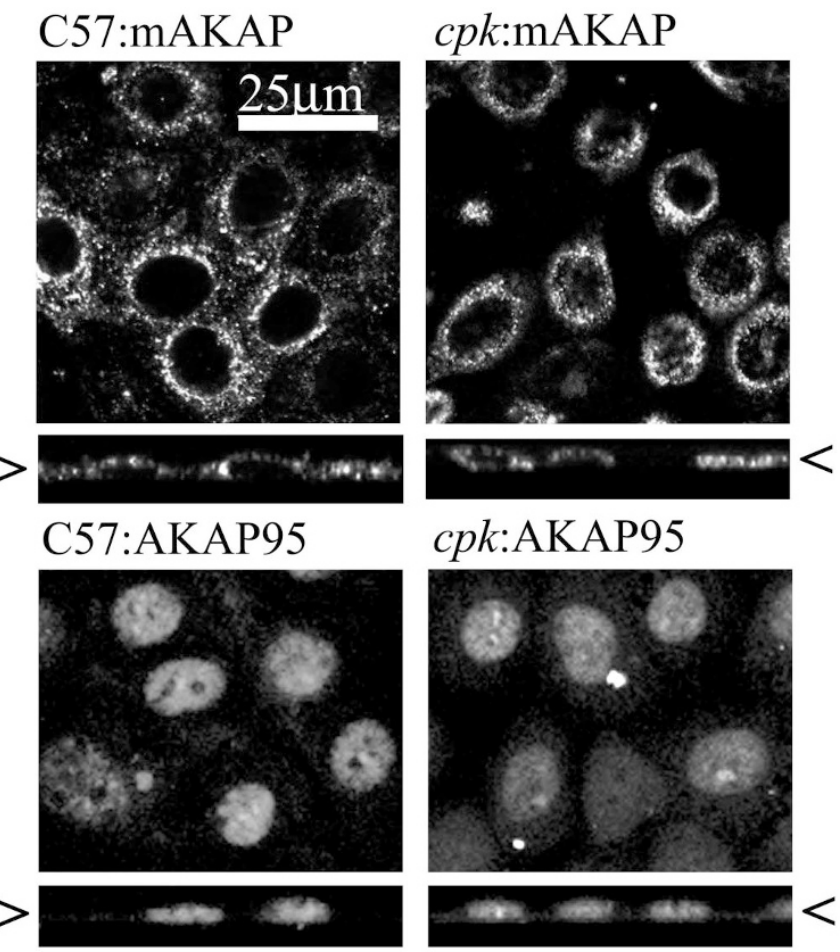

cpk:AKAP95

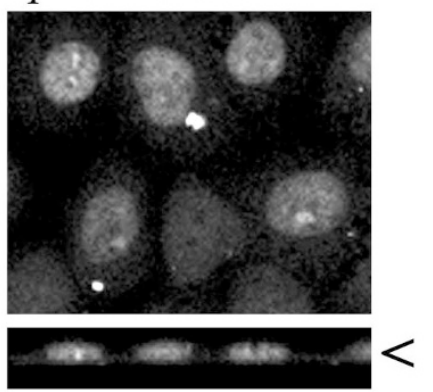

C57:Ezrin

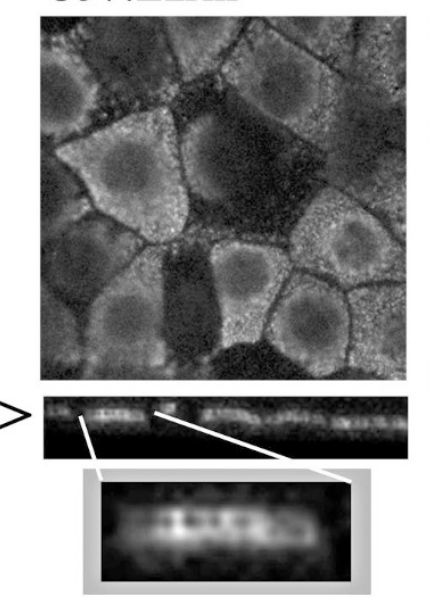

\section{$c p k$ :Ezrin}

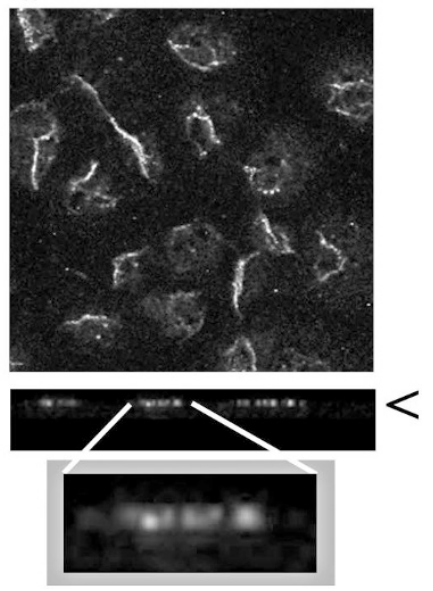

Figure 3. Optical sectioning of confluent principal cell cultures showed that only cpk ezrin expression was abnormal compared with C57 when the subcellular distribution of each AKAP was examined. Samples were prepared and indirect immunofluorescence staining was performed as described in the legend to Figure 2, but only immunoreactive AKAP signals are shown. Samples were viewed by CLSM, and images were captured, as described in "Methods." Large panels are single $x-y$ scans and small panels are $x-z$ cross-sections reconstructed from the full $z$-series of $x-y$ scans. Arrowheads $(>,<)$ indicate the location of the $x-y$ plane shown in the $x-y$ scans. No ezrin immunostaining was detected at the basal surfaces of either C57 or $c p k$ cell cultures, and all cultures were confluent when fixed. Bar represents $25 \mu \mathrm{m}$ in all CLSM images except for the gray-bordered images. To show apparent apical immunostaining, regions of the ezrin cross-sections between the white lines were enlarged as described in "Methods."

scribed above, and separate red (ezrin immunostaining) and green (phalloidin staining to locate cell boundaries, shown only for C57 + EGF, as a combined gray-scale image) images were collected for each region. Images shown are for the predominant phenotype present in each treatment condition. 

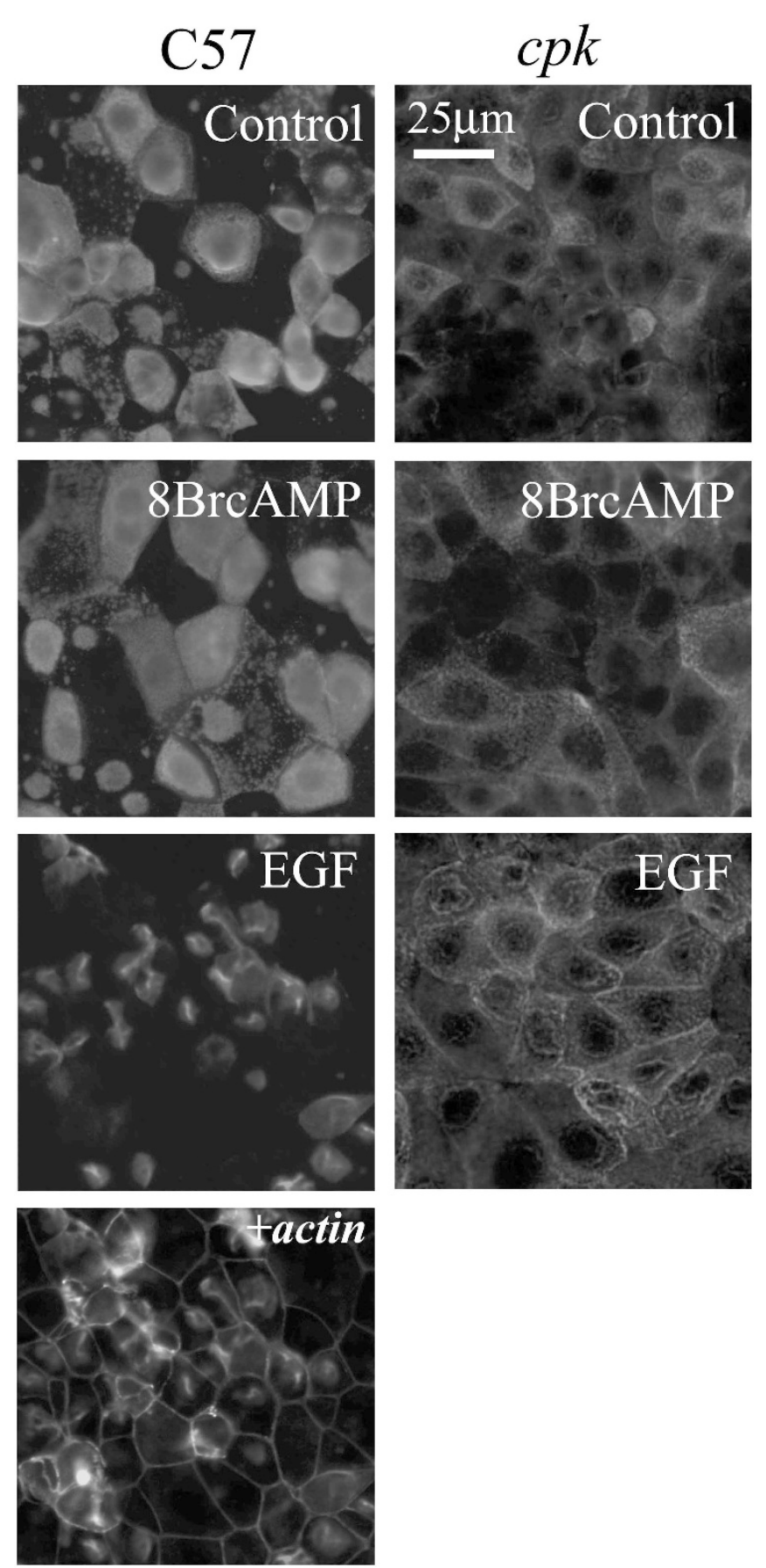

Figure 4. Only $c p k$ ezrin was redistributed within the cell in response to a medium change, but both $\mathrm{C} 57$ and $c p k$ ezrin were redistributed in response to EGF treatment, and a cAMP analog had no effect. Confluent filter-grown cultures of cystic cpk- and noncystic C57-derived principal cells had either fresh medium (Control), or were treated with fresh medium containing $10 \mu \mathrm{M}$ 8-bromo-cAMP ( 8 BrcAMP) or $15 \mathrm{ng} / \mathrm{mL}$ EGF (added to both sides) for 30 min, before fixation as described in "Methods." Immunofluorescent staining for ezrin was performed, samples were viewed by conventional fluorescence microscopy, and 10 images per sample were viewed and prepared, as described in "Methods." Bar corresponds to $25 \mu \mathrm{m}$. Data shown are the predominant phenotype observed in three $c p k$, and one C57, experiments each performed in duplicate. Control conditions at $0 \mathrm{~min}$ were identical to Figure 2 ezrin immunostaining. All cultures were confluent when fixed, as demonstrated by the panel labeled +actin, which shows a gray-scale conversion of the combined red (ezrin immunostaining) and green (phalloidin conjugate staining) layered Adobe PhotoShop image of the data from the C57 + EGF condition directly above it.
Other information. Statistical determinations and protein quantitation were performed, and reagents not specifically listed above were obtained, as described (15).

\section{RESULTS}

To determine whether noncystic- and cystic-derived principal cells expressed AKAPs that might mediate differences in PKA subunit location and regulation of cAMP-mediated cell proliferation previously observed (15), expression of four known AKAPs was examined. Two AKAPs associated with nuclear structures (mAKAP, AKAP95), and two AKAPs associated with the cytoskeleton (ezrin, AKAP-KL) were targeted. The mAKAP has been reported to occur at the nuclear membrane of differentiated myocytes (24) and was reported to provide a base for multiprotein regulation of the cardiomyocyte ryanodine receptor (24-26). AKAP95 is a primarily nuclear matrix protein whose subcellular distribution and ability to associate with the PKA regulatory subunit type II $\alpha$ isoform is cell cycle-dependent (27). AKAP95 has been reported to bind to an RNA helicase, supporting its role in modulating multiprotein regulation of nuclear matrix proteins and assembly of hormonally responsive transcription complexes (27-29). Ezrin is a member of the ERM family, is both an AKAP and an EGFR substrate, is present at the apical cytoplasmic side of many polarized cells, links plasma membrane proteins to the cytoskeleton, and binds other proteins [for reviews, see Bretscher (30) and Weinmann et al. (31)]. AKAP-KL proteins are highly expressed in kidney and lung, have a polarized apical distribution in epithelia, and interact with and modulate actin cytoskeletal structure (32).

As shown (Fig. 1), immunoreactive mAKAP, AKAP95, ezrin, and AKAP-KL proteins were expressed in confluent filter-grown cultures of both noncystic C57- and cystic cpkderived principal cells. Single forms of AKAP95 and ezrin were detected at appropriate apparent molecular weights (95 and $80 \mathrm{kD}$, respectively). An mAKAP protein of $300 \mathrm{kD}$ is the primary form found in brain and heart, but a $255-\mathrm{kD}$ form was also reported (24-26). In principal cell cultures, both mAKAP $300-\mathrm{kD}$ and $255-\mathrm{kD}$ forms were expressed. AKAP-KL has been reported to migrate by SDS-PAGE as several differently sized proteins $(105-133 \mathrm{kD})$ resulting from alternative splicing in whole tissue lysates, although calculated molecular weights for six isoforms ranged from 74 to $98 \mathrm{kD}$ (32). Three immunoreactive AKAP-KL bands of approximately 145, 112, and 68 $\mathrm{kD}$ were variably observed in the untransformed C57- or $c p k$-derived principal cell filter-grown cultures (Fig. 1). Densitometric quantitation of protein expression in each $15-\mu \mathrm{g}$ sample revealed that cystic-derived samples had lower relative expression levels compared with noncystic values (set arbitrarily at 1) of AKAP95, and modestly decreased expression of ezrin, but mAKAP expression was similar (Fig. 1). Owing to the variability observed in AKAP-KL immunoreactivity, quantitation of AKAP-KL expression was not performed.

Cystic- and noncystic-derived cell culture growth and fixation conditions were identical, and all cultures were confluent when fixed for microscopic evaluation, as shown by the green phalloidin staining of lateral F-actin (Fig. 2). Some immuno- 
reactive AKAP-KL was detected by conventional fluorescence microscopy, and although noncystic and cystic expression appeared qualitatively different with some apparent nuclear immunostaining in C57, AKAP-KL localization studies were not pursued further (Fig. 2). The AKAPs mAKAP, AKAP95, and ezrin were detected at appropriate cellular locations within noncystic-derived principal cell cultures (Fig. 2, conventional microscopy; Fig. 3, CLSM). Location in cystic-derived cultures was similar for the perinuclear mAKAP and primarily nuclear AKAP95. In both cell types, ezrin immunostaining was detected by a full $z$-series of CLSM $x-y$ scans only between 6 and $11 \mu \mathrm{m}$ above the filter support, indicating expression at the apical side of the epithelium. Normal ezrin immunostaining differed from cpk ezrin, which was distributed in a nonuniform manner within an apparently narrower apical plane (Fig. 3).

Because ezrin is an EGFR tyrosine kinase substrate (33), cystic principal cells have an abnormal apical EGFR phenotype (34), cpk ezrin is located differently from C57 ezrin within the apical region (Figs. 2 and 3), and inhibition of ezrin tyrosine dephosphorylation was reported to alter its distribution in MDCK cells (35), ezrin distribution was evaluated by examining conventional fluorescence microscopic images of confluent cystic- and noncystic-derived principal cell cultures after stimulation by EGF. As shown (Fig. 4), a 30-min control incubation did not alter ezrin distribution in C57 cells. However, the same control removal and replacement of medium resulted in more diffuse $c p k$ ezrin immunostaining (compare with Fig. 2). Addition of 8-bromo-cAMP, a cell-permeable cAMP analog, had no effect on ezrin distribution in either cell type, compared with the 30 -min controls. Incubation of live cultures with EGF resulted in ezrin redistribution within each confluent cell type, and effects were qualitatively different. EGF-treated C57 cells appeared to have an ezrin phenotype comparable to untreated cpk cells (compare with Figs. 2 and 3). As shown (Fig. 4, bottom left), EGF-treated C57 cells maintained normal cell boundaries as indicated by phalloidin staining of lateral actin, as did all other samples (data not shown). EGF-treated cpk cells had a different ezrin phenotype altogether, in which ezrin immunostaining appeared concentrated at lateral edges and within the cell in a unique pattern.

\section{DISCUSSION}

Four AKAPs (mAKAP, AKAP95, AKAP-KL, and ezrin) previously reported to mediate PKA anchoring were expressed in primary principal cell cultures from murine noncystic and ARPKD kidneys. These data demonstrate renal epithelial expression of mAKAP, an AKAP originally identified in skeletal muscle whose role in renal epithelia is unknown. Qualitatively more AKAP95 was detected in cystic nuclei, in spite of lower overall expression, perhaps reflecting a difference in cell cycle status between the two cell types, which have been shown to have strikingly different basal proliferation levels (15). As it is likely that altered gene expression regulates the altered cell proliferation observed in PKD, perhaps the apparent AKAP95 down-regulation observed for $c p k$ resulted in loss of a normal PKA-regulated proliferation control mechanism (15). The variable AKAP-KL expression observed suggests that a more detailed analysis is required to characterize the many AKAP-KL forms reported to arise from alternative splicing (32). The qualitatively different subcellular distribution observed for $c p k$ ezrin suggested abnormal distribution within the apical microvillar or cytoskeletal region of the principal cell epithelium. Apical actin appeared normal (15), so it is likely that characteristic blunt, sparse microvilli were present in both principal cell cultures. We speculate that in the absence of a functional PKD gene product, cpk cell ezrin may associate abnormally with apical PKA regulatory subunits. More or less PKA at the $c p k$ cell apical surface that is associated with ezrin, or with another apical AKAP, could change PKA-dependent regulation of epithelial transport (and perhaps proliferative) functions to mediate cystogenesis.

Full-length ERM proteins are present in soluble cell fractions in a dormant, folded form in which an intramolecular interaction prevents binding to other proteins. Conformational activation, by Rho-kinase-dependent phosphorylation of ezrin on T567, to the actin-binding oligomeric form unmasks binding sites for other proteins, such as the Rho-GDP-dissociation inhibitor RhoGDI, phosphatidylinositol 3-kinase regulatory subunit p85, and a family of ezrin binding proteins, findings that have led to the suggestion that ERMs have potential roles in signaling pathways [for reviews, see Weinmann et al. (31) and Bretscher et al. (36)]. Support for a signaling role of ezrin was demonstrated by EGF- and hepatocyte growth factorinduced phosphorylation of the same two residues, Y146 and Y354 [for review, see Bretscher et al. (36)]. Tyrosine phosphorylation of ezrin by hepatocyte growth factor through its receptor, c-met, was implicated in regulation of branching tubulogenesis in the epithelial cell line, LLC-PK1 (37).

In plastic-grown MDCK cells, pervanadate inhibition of Y146 and Y354 dephosphorylation led to ezrin redistribution (35), and some of the resulting microscopic data were qualitatively similar to those reported here. The previous report demonstrated altered ezrin distribution within the apical region and the cytoplasm, and increased intensity of immunostaining at cell borders, in response to pervanadate incubation. The authors concluded that the change indicated cytosol to plasma membrane redistribution of tyrosine-phosphorylated ezrin (35). For experiments in both the previous report (35) and the present study, growth medium was removed from epithelial layers and replaced with treatment medium for $30 \mathrm{~min}$ before fixation. Therefore, it is possible that the apparent ezrin redistribution observed in both studies was partly the result of disruptions of the apical epithelial surface as a result of acute medium changes. However, if cystin, the Cys 1 gene product disrupted in $c p k$, is associated with apical cilia, which have been postulated to act as flow sensors (2), then perhaps ciliary malfunction could account for the greater apparent ezrin disruption by medium change observed in cpk- compared with C57-derived cultures. However, a quantitative evaluation of CLSM ezrin immunostaining and phosphorylation status in cultures treated without a complete medium change will be required to demonstrate whether ezrin redistributes in epithelial cells in response to tyrosine phosphorylation, as suggested previously (35). 
Evidence for cellular signaling through the AKAP feature of ezrin (38) has been demonstrated by its ability to provide PKA regulation of: the $\mathrm{Na}-\mathrm{H}$ exchanger through an interaction with an EBP50 family member, $\mathrm{Na}-\mathrm{H}$ exchanger regulatory factor 1 [for review, see Weinmann et al. (31)]; the cystic fibrosis transmembrane conductance regulator through an interaction with E3KARP (39); and the $\beta$-adrenergic receptor through an interaction with $\mathrm{Na}-\mathrm{H}$ exchanger regulatory factor 2 (40). Nothing is known about the cellular function of this feature in tubulogenesis or cystogenesis. However, PKA phosphorylates RhoA on S188 to inhibit and then block activation of Rho kinase, leading to loss of stress fibers [for reviews, see Bretscher et al. (36), Diviani et al. (41), and Sah et al. (42)]. We previously reported disrupted actin stress fibers in the same $c p k$ principal cell culture system used in the present study (15), and also have observed disrupted stress fibers in a conditionally immortalized principal cell culture system for another murine ARPKD model $(43,44)$. Perhaps altered PKA targeting by ezrin has the potential to interfere with the activation of ezrin by Rho kinases and subsequent membrane-cytoskeletal linkage and function.

\section{CONCLUSIONS}

There have been several recent reports that other PKD models have altered stress fibers (45) and altered expression of cytoskeletal organization genes $(22,46)$; that Rho family proteins are involved in renal tubulogenesis (47) and cytoskeletal regulation of cAMP-mediated aquaporin-2 translocation (48); and that polycystin-1 induced morphologic changes in MDCK cells that required phosphatidylinositol 3-kinase (49). These seemingly disparate phenomena led us to speculate that in combination with the abnormal apical EGFR phenotype common to all PKDs [for review, see Sweeney et al. (50)], ezrin could provide an integration point for abnormal signaling in PKD.

Acknowledgments. The authors thank Drs. Ellis D. Avner and Cathleen R. Carlin for helpful comments and suggestions.

\section{REFERENCES}

1. Davis ID, MacRae Dell K, Sweeney WE, Avner ED 2001 Can progression of autosomal dominant and autosomal recessive polycystic kidney disease be prevented? Semin Nephrol 21:430-440

2. The European Polycystic Kidney Disease Consortium 1994 The polycystic kidney disease 1 gene encodes a $14 \mathrm{~kb}$ transcript and lies within a duplicated region on chromosome 16. Cell 77:881-894

3. The International Polycystic Kidney Disease Consortium 1995 Polycystic kidney disease: the complete structure of the $P K D I$ gene and its protein. Cell 81:289-298

4. Ward CJ, Hogan MC, Rosetti S, Walker D, Snedden T, Wang X, Kubly V, Cunningham JM, Bacallao R, Ishibashi M, Milliner DS, Torres VE, Harris PC 2002 The gene mutated in autosomal recessive polycystic kidney disease encodes a large, receptor-like protein. Nat Genet 30:259-269

5. Onuchic LF, Furu L, Nagasawa Y, Hou X, Eggermann T, Ren Z, Bergmann C, Senderek J, Esquivel E, Zeltner R, Rudnik-Schoneborn S, Mrug M, Sweeney W, Avner ED, Zerres K, Guay-Woodford LM, Somlo S, Germino GG 2002 PKHD1, the polycystic kidney and hepatic disease 1 gene, encodes a novel large protein containing multiple immunoglobulin-like plexin-transcription-factor domains and paralle beta-helix 1 repeats. Am J Hum Genet 70:1305-1317

6. Hou X, Mrug M, Yoder BK, Lefkowitz EJ, Kremmidiotis G, D’Eustachio P, Beier DR, Guay-Woodford LM 2002 Cystin, a novel cilia-associated protein, is disrupted in the $c p k$ mouse model of polycystic kidney disease. J Clin Invest 109:533-540

7. Moyer JH, Lee-Tischler MJ, Kwon HY, Schrick JJ, Avner ED, Sweeney WE, Cacheiro NL, Wilkinson JE, Woychik RP 1994 Candidate gene associated with a mutation causing recessive polycystic kidney disease in mice. Science 264:1329_ 1333
8. Boletta A, Qian F, Onuchic LF, Bhunia AK, Phakdeekitcharoen B, Hanaoka K, Guggino W, Monaco L, Germino GG 2000 Polycystin-1, the gene product of PKD1, induces resistance to apoptosis and spontaneous tubulogenesis in MDCK cells. Mol Cell 6:1267-1273

9. Nickel C, Benzing T, Sellin L, Gerke P, Karihaloo A, Liu Z-X, Cantley LG, Walz G 2002 The polycystin-1 C-terminal fragment triggers branching morphogenesis and migration of tubular kidney epithelial cells. J Clin Invest 109:481-489

10. Francis SH, Corbin JD 1999 Cyclic nucleotide-dependent protein kinases: intracellular receptors for cAMP and cGMP action. Crit Rev Clin Lab Sci 36:275-328

11. Shih M, Lin F, Scott JD, Wang HY, Malbon CC 1999 Dynamic complexes of $\beta_{2}$-adrenergic receptors with protein kinases and phosphatases and the role of gravin. J Biol Chem 274:1588-1595

12. Westphal RS, Tavalin SJ, Lin JW, Alto NM, Fraser ID, Langeberg LK, Sheng M, Scott JD 1999 Regulation of NMDA receptors by an associated phosphatase-kinase signaling complex. Science 285:93-96

13. Steinberg SF, Brunton LL 2001 Compartmentation of $G$ protein-coupled signaling pathways in cardiac myocytes Annu Rev Pharmacol Toxicol 41:751-773

14. Orellana SA, Marfella-Scivittaro C 2000 Distinctive cyclic AMP-dependent protein kinase subunit localization is associated with cyst formation and loss of tubulogenic capacity in Madin Darby Canine Kidney cell clones. J Biol Chem 275:21233-21240

15. Marfella-Scivittaro C, Quiñones A, Orellana SA 2002 Cyclic AMP-dependent protein kinase and proliferation differ in normal and polycystic kidney epithelia. Am J Physiol: Cell Physiol 282:C693-C707

16. Orellana SA, Neff CD, Sweeney WE, Avner ED 1996 Novel Madin Darby Canine Kidney cell clones exhibit unique phenotypes in response to morphogens. In Vitro Cell Dev Biol Anim 32:329-339

17. Orellana SA, Quiñones AM 2002 Prostaglandin $E_{1}$ induces constitutive proliferation in murine polycystic kidney principal cells. J Am Soc Nephrol 13:113A(abstr)

18. Calvet JP, Grantham JJ 2001 The genetics and physiology of polycystic kidney disease. Semin Nephrol 21:107-123

19. Russell ES, McFarland EC 1977 Cystic kidneys. Mouse Newsletter 56:40-43

20. Avner ED 1993 Renal developmental diseases. Semin Nephrol 13:427-435

21. Sweeney WE, Avner ED 1998 Functional activity of epidermal growth factor receptors in autosomal recessive polycystic kidney disease. Am J Physiol 275:F387-F394

22. Liu S, Obara-Ishihara T, Drummond IA, Beier DR 2002 Characterization of Nek8, the gene mutated in the $j c k$ mouse model of polycystic kidney disease. J Am Soc Nephrol 13:116A(abstr)

23. Cowley Jr BD, Ricardo SD, Nagao S, Diamond JR 2001 Increased renal expression of monocyte chemoattractant protein-1 and osteopontin in ADPKD in rats. Kidney Int 60:2087-2096

24. Kapiloff MS, Schillace RV, Westphal AM, Scott JD 1999 mAKAP: an A-kinase anchoring protein targeted to the nuclear membrane of differentiated myocytes. J Cell Sci 112:2725-2736

25. Kapiloff MS, Jackson N, Airhart N 2001 mAKAP and the ryanodine receptor are part of a multi-component signaling complex on the cardiomyocyte nuclear envelope. J Cell Sci 114:3167-3176

26. Dodge KL, Khouangsathiene S, Kapiloff MS, Mouton R, Hill EV, Houslay MD, Langeberg LK, Scott JD 2001 mAKAP assembles a protein kinase A/PDE4 phosphodiesterase cAMP signaling module. EMBO J 20:1921-1930

27. Eide T, Coghlan V, Orstavik S, Holsve C, Solberg R, Skalhegg BS, Lamb NJ, Langeberg L, Fernandez A, Scott JD, Jahnsen T, Tasken K 1998 Molecular cloning, chromosomal localization, and cell cycle-dependent subcellular distribution of the A-kinase anchoring protein, AKAP95. Exp Cell Res 238:305-316

28. Akileswaran L, Taraska JW, Sayer JA, Gettemy JM, Coghlan VM 2001 A-kinase anchoring protein AKAP95 is targeted to the nuclear matrix and associates with p68 RNA helicase. J Biol Chem 276:17448-17454

29. Collas P, Le Guellec K, Tasken K 1999 The A-kinase-anchoring protein AKAP95 is a multivalent protein with a key role in chromatin condensation at mitosis. J Cell Biol 147:1167-1180

30. Bretscher A 1999 Regulation of cortical structure by the ezrin-radixin-moesin protein family. Curr Opin Cell Biol 11:109-116

31. Weinman EJ, Minkoff C, Shenolikar S 2000 Signal complex regulation of renal transport proteins: NHERF and regulation of NHE3 by PKA. Am J Physiol: Renal Physiol 279:F393-F399

32. Dong F, Feldmesser M, Casadevall A, Rubin CS 1998 Molecular characterization of a cDNA that encodes six isoforms of a novel murine A kinase anchor protein. J Biol Chem 273:6533-6541

33. Hunter T, Cooper JA 1981 Epidermal growth factor induces rapid tyrosine phosphorylation of proteins in A431 human tumor cells. Cell 24:741-752

34. Orellana SA, Sweeney WE, Neff CD, Avner ED 1995 Epidermal growth factor receptor expression is abnormal in murine polycystic kidney. Kidney Int 47:490-499

35. Wu Y-X, Uezato T, Fujita M 2000 Tyrosine phosphorylation and cellular redistribution of ezrin in MDCK cells treated with pervanadate J Cell Biochem 79:311-321

36. Bretscher A, Chambers D, Nguyen R, Reczek D 2000 ERM-merlin and EBP50 protein families in plasma membrane organization and function. Annu Rev Cell Dev Biol 16:113-143

37. Crepaldi T, Gautreau A, Comoglio PM, Louvard D, Arpin M 1997 Ezrin is an effector of hepatocyte growth factor-mediated migration and morphogenesis in epithelial cells. J Cell Biol 138:423-434

38. Dransfield DT, Bradford AJ, Smith J, Martin M, Roy C, Mangeat PH, Goldenring JR 1997 Ezrin is a cyclic AMP-dependent protein kinase anchoring protein. EMBO J 16:35-43

39. Sun F, Hug MJ, Lewarchik CM, Yun CH, Bradbury NA, Frizzell RA 2000 E3KARP mediates the association of ezrin and protein kinase A with the cystic fibrosis transmembrane conductance regulator in airway cells. J Biol Chem 275:29539-29546 
40. Cao TT, Deacon HW, Reczek D, Bretscher A, von Zastrow M 1999 A kinaseregulated PDZ-domain interaction controls endocytic sorting of the $\beta_{2}$-adrenergic receptor. Nature 401:286-290

41. Diviani D, Soderling J, Scott JD 2001 AKAP-Lbc anchors PKA, and nucleates G $\alpha 12$ selective Rho mediated stress fiber formation. J Biol Chem 276:44247-44257

42. Sah VP, Seasholtz TM, Sagi SA, Brown JH 2000 The role of Rho in G proteincoupled receptor signal transduction. Annu Rev Pharmacol Toxicol 40:459-489

43. Mandapat ML, Quiñones AM, Orellana SA 2002 Ezrin associates with membranes and protein kinase A (PKA) in conditionally immortalized principal cells from murine polycystic kidney. J Am Soc Nephrol 13:108A(abstr)

44. Sweeney Jr WE, Kusner L, Carlin C, Chang S, Futey L, Cotton CU, Dell KM, Avne ED 2001 Phenotypic analysis of conditionally immortalized cells isolated from the BPK model of ARPKD. Am J Physiol: Cell Physiol 281:C1695-C1705

45. Cai Y, Lee K-B, Geng L, Tian X, Nishimura S, Zeltner R, Shibazaki S, Anyatonwu G, Mei C, Ehrlich B, Somlo S $2002 \mathrm{COOH}$-terminal phosphorylation is required for polycystin-2 function. J Am Soc Nephrol 13:47A(abstr)
46. Perry SJ, Baillie GS, Kohout TA, McPhee I, Magiera MM, Ang KL, Miller WE, McLean AJ, Conti M, Houslay MD, Lefkowitz RJ 2002 Targeting of cyclic AMP degradation to beta 2-adrenergic receptors by beta-arrestins. Science 298:834836

47. Rogers KK, Jou T-S, Guo W, Lipschutz JH 2002 The Rho family of GTPases is involved in epithelial cystogenesis and tubulogenesis. J Am Soc Nephrol 13:101A(abstr)

48. Tamma G, Klussmann E, Procino G, Svelto M, Rosenthal W, Valenti G 2002 RhoA inhibition through Rho phosphorylation and interaction with RhoGDI is a key event for cytoskeletal dynamics controlling cAMP-induced AQP2 translocation. J Am Soc Nephrol 13:484A(abstr)

49. Boletta A, Qian F, Bhunia AK, Germino GG 2002 PKD1-induced morphological changes in MDCK cells require PI3kinase. J Am Soc Nephrol 13:105A(abstr)

50. Sweeney WE, Chen Y, Nakanishi K, Frost P, Avner ED 2000 Treatment of polycystic kidney disease with a novel tyrosine kinase inhibitor. Kidney In $57: 33-40$ 